\title{
Significados do mundo do crime para adolescentes em medida socioeducativa de internação, Brasil
}

\section{Vinicius Coscioni}

Universidade Federal do Rio Grande do Sul, Brasil*

Bruno Graebin de Farias

Universidade Federal do Rio Grande do Sul, Brasil**

viniciuscoscioni@gmail.com

\author{
Edinete Maria Rosa \\ Universidade Federal do Espírito Santo, Brasil *** \\ Sílvia Helena Koller \\ Universidade Federal do Rio Grande do Sul, \\ Brasil ${ }^{\star \star \star *}$
}

Resumo (analítico)

O objetivo deste estudo é investigar significados atribuídos ao mundo do crime por adolescentes em medida socioeducativa de internação. Os participantes do estudo foram 25 adolescentes (15 a 19 anos) do sexo masculino internados em quatro unidades socioeducativas nos Estados do Rio Grande do Sul e Espírito Santo, Brasil. Foram realizados dois grupos focais em cada Estado, interpretados por Análise Temática. Os significados expressos pelos participantes revelaram que a vinculação ao mundo do crime atende a necessidades de segurança econômica, fortalecimento da identidade pessoal, reconhecimento social, senso de pertencimento e proteção física, consistindo em um processo de resiliência oculta. A compreensão das perspectivas dos adolescentes sobre o mundo do crime pode informar práticas de atendimento capazes de atender necessidades materiais e simbólicas e prevenir riscos.

\section{Palavras-chave}

Tráfico de drogas; crime; adolescente em conflito com a lei; medidas socioeducativas; prevenção do crime.

\section{Tesauro}

Biblioteca Virtual em Saúde-Psicologia/BVS-Psi
Para citar este artículo

Coscioni, V., Farias, B. G, Rosa, E. M., \& Koller, S. H. (2019). Significados do mundo do crime para adolescentes em medida socioeducativa de internação, Brasil. Revista Latinoamericana de Ciencias Sociales, Niñez y Juventud, 17(2), 1-20. doi: $10.11600 / 1692715 \times .17214$

Historial

Recibido: 30.07.2018

Aceptado: 17.10.2018

Publicado: 31.06.2019

Información artículo

Este artigo é derivado da pesquisa «Projetos de Vida e Relações Interpessoais de Adolescentes em Cumprimento de Medida Socioeducativa de Internação», com financiamento da Coordenação de Aperfeiçoamento de Pessoal de Nível Superior (Capes) aprovado pelo Comitê de Ética do Centro de Ciências Humanas e Naturais da Universidade Federal do Espírito Santo ( $n^{\circ}$ CAEE 51975115.9.0000. 5542). Realizada entre 16 de março de 2015 e 13 de março de 2017. Área: Ciencias Sociales. Subárea: Sociología. 


\section{Meanings of the 'world of crime' for adolescents at treatment facilities, Brazil}

Abstract (analytical)

This study aims to comprehend meanings of the world of crime among adolescents at treatment facilities. The participants of this study were 25 male adolescents (15 to 19 years) at four treatment facilities in the states of Espírito Santo and Rio Grande do Sul, Brazil. Two focal groups in each state were held, interpreted using the Thematic Analysis technique. The meanings expressed by participants revealed that their affiliation with the world of crime meets their needs of economic security, strengthening of personal identity, social recognition, sense of belonging, and physical protection. Their involvement in the world of crime consists of a hidden resilience process. The comprehension of adolescents' perspectives of the world of crime can inform services so that they are able to meet their material and symbolic needs and prevent risks.

Keywords

Drug trafficking, crime, juvenile delinquency, institutionalized adolescents, crime prevention.

\section{Significados del «mundo del crimen» para adolescentes en unidades socioeducativas, Brasil}

Resumen (analítico)

El objetivo de este estudio es comprender significados del mundo del crimen para adolescentes internados en unidades socioeducativas. Los participantes del estudio fueron 25 adolescentes (15 a 19 años) del sexo masculino internados en cuatro unidades en los Estados del Rio Grande do Sul y Espírito Santo, Brasil. Fueron realizados dos grupos focales en cada Estado, interpretados por Análisis Temático. Los significados expresados por los participantes han revelado que la afiliación al mundo del crimen atiende a necesidades de seguridad económica, fortalecimiento de la identidad personal, reconocimiento social, sentido de pertenencia y protección física, lo que consiste un proceso de resiliencia oculta. La comprensión de las perspectivas de los adolescentes sobre el mundo del crimen puede generar prácticas de tratamiento capaces de satisfacer necesidades materiales y simbólicas y prevenir riesgos.

\section{Palabras-clave}

Tráfico de drogas, crimen, adolescente en conflicto con la ley, medidas socioeducativas, prevención del crimen.

\section{Información autores}

[*] Doutorando pelo Programa de Pós-Graduação em Psicologia da Universidade Federal do Rio Grande do Sul e pesquisador visitante na Faculdade de Psicologia e Ciência da Educação, Universidade de Coimbra, Portugal. Orcid: 0000-0003-4007-957X. H5: 0. Endereço eletrônico: viniciuscoscioni@gmail.com

[**] Doutorando pelo Programa de Pós-Graduação em Psicologia da Universidade Federal do Rio Grande do Sul. Orcid: 0000-0002-7323-8621. H5: 0. Endereço eletrônico: brunograebin@gmail.com

[***] Professora Associada do Programa de Pós-Graduação em Psicologia da Universidade Federal do Espírito Santo. Orcid: 0000-0003-4279-8308. H5: 9. Endereço eletrônico: edineter@gmail.com

[****] Professora Titular do Programa de Pós-Graduação em Psicologia da Universidade Federal do Rio Grande do Sul. Orcid: 0000-0001-9109-6674. H5: 42. Endereço eletrônico: silvia.koller@gmail.com 


\section{Introdução}

O objetivo desta pesquisa é conhecer os significados atribuídos ao «mundo do crime» por adolescentes em medida socioeducativa (MSE) de internação no Espírito Santo (ES) e Rio Grande do Sul (RS), Brasil. Como MSEs compreendem-se as medidas judiciais aplicadas a adolescentes responsabilizados pela prática de atos infracionais. Seu cumprimento em regime de internação é delegado nos casos de atos infracionais mais graves ou reincidência em atos infracionais menos graves (Brasil, 1990). O conceito de «mundo do crime», por sua vez, é compreendido por Feltran (2008) como uma categoria êmica que representa o conjunto de códigos e sociabilidades associadas aos negócios ilícitos do narcotráfico, bem como roubos e furtos.

O mundo do crime se expressa nos territórios brasileiros por meio de «facções», que consistem em redes de operação do narcotráfico com domínio territorial sobre as favelas e bloqueios ao acesso da polícia por meio de conflitos armados (Lessing, 2008). As facções brasileiras mais antigas originaram-se com a busca pela organização de um caixa comum entre os presos e na viabilização de operações de fuga e «resgate» da prisão (Cipriani, 2016), como o «Comando Vermelho» (Rio de Janeiro) e a «Falange Gaúcha» (Rio Grande do Sul). O «Primeiro Comando da Capital» (São Paulo) teve sua origem de forma distinta, centrada sobretudo na imposição de regras comuns entre os presos como forma de monopolizar a violência e o enfrentamento das condições precárias e maus-tratos nas prisões (Cipriani, 2016). Em Porto Alegre/RS, o domínio das diferentes facções foi historicamente distribuído por critérios geográficos, sem a existência de uma «guerra aberta». Entretanto, tal quadro tornou-se instável com o crescimento da facção «Bala na Cara» e, posteriormente, da coalizão formada em sua oposição («Bala nos Bala», «AntiBala», ou «Anti»), que hoje disputam os pontos de venda de drogas (Cipriani, 2016).

O nível de organização das facções está diretamente correlacionado ao grau de concentração do mercado de drogas no local em que operam - que varia desde o microtráf1co (individual) ao monopólio de uma facção sobre o mercado de drogas (Lessing, 2008). 
No estudo etnográfico de Feltran (2008), a análise situou-se em territórios periféricos da metrópole de SP, nos quais a dinâmica do mundo do crime se expandiu e estabeleceu novas relações com diversas dimensões da vida cotidiana nas periferias urbanas. Mattos (2016) analisou a relação do mundo do crime com as demais esferas da «vida na favela», no RJ, identificando que moradores e moradoras acionam negociações políticas com as facções locais a fim de dissuadir conflitos e operar uma «manutenção da paz». Lessing (2008) descreveu as relações entre as facções e as comunidades a partir do estabelecimento de uma «ordem pública», além da presença de ações assistenciais em esquemas de troca de favores - nos quais moradores das comunidades devem manter uma postura de cumplicidade com a facção. Todavia, a relação entre facções e comunidades é também marcada por violências, extorsões e pela reprodução de estigmas e classificações discriminatórias (Azevedo \& Cipriani, 2015), constituindo relações complexas e contraditórias que não podem ser reduzidas simplesmente a «simpatia» ou «conivência».

As facções são reconhecidas também pelo aliciamento de adolescentes ao tráfico de drogas, o que é analisado por Feltran (2008) como um processo de imersão gradual na criminalidade. Em um estágio inicial, há uma dicotomia clara entre o mundo familiar/ legítimo e o mundo do crime, passando pela aproximação e convivência com pessoas vinculadas ao crime. A imersão no mundo do crime inicia-se, então, de modo hesitante e não-identificado («falta de coragem»), motivada muito frequentemente pelo acesso fácil a bens de consumo. Pouco a pouco, a ação criminal é assumida como rito de passagem, passando ao uso progressivo da violência nas ações criminais e à expansão dos atos violentos nas relações cotidianas. Lentamente a vida transforma-se em uma sucessão de ações criminais, o que com o passar do tempo pode gerar a perda dos laços sociais e, mais adiante, a aceitação radical da própria morte. Outros eventos marcantes foram também destacados por Feltran (2008), como os conflitos frequentes com a polícia; a institucionalização em unidade socioeducativa; a naturalização da circulação por espaços de privação de liberdade; a vivência de perdas de pessoas próximas pela «guerra do tráfico»; a «desilusão» com o «mundo do crime»; os conflitos para sair do mundo do crime; e a busca por ganhar a confiança «de ladrão e de trabalhador».

A emergência das sociabilidades violentas da juventude associada ao narcotráfico é, portanto, resultado da complexa interação entre diversos fatores. Dentre eles, Zaluar (2012) destaca: a pobreza; a exposição à violência; a desesperança quanto a possibilidades de ascensão social por «meios legítimos»; a desorganização social das comunidades periféricas e fragmentação intergeracional; o trabalho informal e explorado; a cultura de con- 
sumo conspícuo; a hipermasculinidade associada à formação de um «ethos guerreiros» etc. Misse (2010) descreve o processo de identificação com a sociabilidade violenta e o estigma associados ao mundo do crime como um fenômeno de produção de subjetividade denominado «sujeição criminal», atribuindo uma dimensão de agência ao sujeito identificado pelo estigma. A partir dessa perspectiva, a imersão no mundo do crime envolve não somente aspectos econômicos e contextuais, mas também subjetivos e identitários.

Ao analisar o caráter polissêmico do termo «adolescente em conflito com a lei» e os «desentendimentos» e implicações de seus diversos significados, Feltran (2011) contesta a ideia de que tais adolescentes vivem à margem do Estado. $\mathrm{O}$ autor aponta a existência de um oposto: um excesso de intervenções do Estado e de sua subjetivação como «sujeitos ilegais» por meio da inserção em um circuito formado por fichas, cadastros, prontuários, perícias, audiências, abordagens policiais e unidades socioeducativas. Por fim, Feltran (2011) também critica a noção de «adolescente em conflito com a lei», termo que sugere uma ausência de leis e regras operando em suas condutas. Feltran (2011) aponta que tais adolescentes enunciam e reivindicam princípios morais, normas de conduta e juízos sobre os pares, muitas vezes chamando esses códigos e sua aplicação de «lei» —outra «lei» que não a lei do Estado. Tal diversidade de significados se expressa em tensões conceituais que se convertem em práticas no âmbito socioeducativo- como as dicotomias entre coerção e negociação; «sujeitos duros» e «sujeitos modificáveis»; e entre «sujeitos carentes»e «sujeitos em desenvolvimento» (Valdenegro \& Calderón-Flández, 2016).

Jimenez e Frassetto (2015) discutem a questão da «lei em conflito com o adolescente» a partir da análise da violência de Estado, de modo a observar uma concentração da violência em um nicho específico da população. Os autores chegam a tal entendimento com base na constatação de sobreposição de perfil entre os adolescentes em MSE de meio aberto e os adolescentes vítimas de homicídio no Brasil: sexo masculino, pobres, com baixa escolaridade e vivendo nas regiões suburbanas dos grandes centros urbanos. Para Candelas (2016), a configuração de uma «Justiça Juvenil» institucionaliza uma dicotomia entre «infância protegida» e «infância perigosa», o que pode acarretar na desconsideração das condições de privação e violência vivenciadas por adolescentes em conflito com a lei.

A «questão das drogas» é frequentemente associada com a prática de atos infracionais - embora a relação entre ato infracional e drogas seja plural e mais ampla que a questão do uso ou dependência química, envolvendo principalmente o modo de participação dos adolescentes no tráfico de drogas (Jimenez, Andrade, \& Bianchini, 2016). Por 
meio de uma abordagem etiológica, Rolim (2014) investigou o recrutamento de adolescentes por facções em Porto Alegre/RS, verificando que a inserção nas facções era acompanhada de um «treinamento violento», a partir do qual se recebia instruções diretas sobre como exercer a violência no mundo do crime. Com tal inserção, as facções ofereciam vivências, tanto de poder e status quanto de riqueza material, que funcionavam como oportunidades não disponibilizadas para adolescentes em situação de vulnerabilidade social. Partindo de uma perspectiva psicológica, um estudo realizado no interior de SP (Pessoa, Coimbra, Noltemeyer, \& Bottrell, 2017) encontrou resultados semelhantes. Os participantes entrevistados associaram o envolvimento com o tráfico de drogas ao aumento do poder de compra, ao acesso a relações afetivo-sexuais e maior status social e à possibilidade de apoiar financeiramente suas famílias. Por tal razão, Pessoa et al. (2017) identificaram a vinculação ao tráfico de drogas como um processo de «resiliência oculta».

Resiliência oculta consiste em processos de enfrentamento e superação de adversidades por meio de comportamentos que, segundo padrões sociais normativos, podem ser compreendidos inicialmente como de risco (Ungar, 2004). A noção de resiliência oculta difere da noção clássica de resiliência - centrada em comportamentos saudáveis apresentados diante de estressores e adversidade em contraposição a comportamentos de risco que indicariam maior vulnerabilidade (Poletto \& Koller, 2008). A ideia de resiliência oculta embasa-se sobretudo em pressupostos construtivistas, a partir dos quais se entende que as pessoas atribuem significados pessoais a fenômenos que elas entram em contato durante sua experiência no mundo. Tais pressupostos teóricos enfatizam a importância da condução de pesquisas em caráter êmico, isto é: baseadas na compreensão dos significados expressos pelos participantes.

A partir do reconhecimento do caráter polissêmico do «mundo do crime» e do «conflito com a lei», o objetivo deste estudo foi investigar os significados atribuídos ao «mundo do crime» por adolescentes em MSE de internação. Portanto, a questão central da pesquisa foi: Quais são os significados atribuídos ao mundo do crime por adolescentes em MSE de internação? Para responder a esta questão, foram utilizados dados coletados em atividades de grupos focais desenvolvidos com adolescentes em MSE de internação em dois Estados brasileiros, ES e RS. Ainda que os grupos focais inicialmente buscavam compreender os projetos de vida e as relações interpessoais de adolescentes em MSE de internação, os participantes trouxeram espontaneamente muito conteúdo referente aos significados que atribuíam ao mundo do crime. Este material foi analisado e compõe o escopo do presente artigo. 


\section{Método}

A pesquisa se configura como um estudo de casos múltiplos conforme as orientações metodológicas de Stake (2006). A ênfase do estudo de casos foi, sobretudo, no objeto de estudo em destaque (o que Stake intitula quintain: termo utilizado para se referir ao objeto de estudo no estudo de caso, podendo ser um fenômeno, um evento, uma pessoa etc.) Nesse sentido, em vez de descrever cada um dos casos que compõem o estudo, a maior preocupação foi compreender o quintain a partir da observação de como ele se apresentava nos diferentes casos.

\section{Contexto}

A pesquisa foi realizada em quatro unidades socioeducativas, duas delas localizadas em Cariacica, Região Metropolitana do ES; e duas delas em Porto Alegre/RS. O sistema socioeducativo capixaba (termo que designa origem no ES) é composto por 12 programas socioeducativos de meio fechado, oito na Região Metropolitana e quatro no interior. Dentre os programas na Região Metropolitana, dois são casas de semiliberdade, dois são originalmente destinados ao cumprimento de internação provisória, três são oficialmente unidades de internação e um é destinado a adolescentes do gênero feminino. O sistema socioeducativo gaúcho gaúcho (termo que designa origem no RS) é composto por 21 programas socioeducativos de meio fechado, sete na Região Metropolitana e 14 no interior. Dentre os programas sediados em Porto Alegre, um é casa de semilibedade, um é destinado ao cumprimento da internação provisória, quatro são unidades de internação e um é destinado a adolescentes do gênero feminino. A pesquisa foi conduzida em unidades para o público masculino já em cumprimento de MSE de internação.

As regiões metropolitanas onde as coletas de dados foram conduzidas apresentam diferentes caracteríticas quanto ao território e contigente populacional. A Grande Vitória/ES possui aproximadamente $2.3 \mathrm{mil} \mathrm{km²}$, é composta por sete municípios (Instituto Brasileiro de Geografia e Estatística-Ibge, 2016a) e apresentava, em 2016, uma estimativa de 1,9 milhões de habitantes (Instituto Brasileiro de Geografia e EstatísticaIbge, 2016b). A Grande Porto Alegre/RS, por sua vez, possui aproximadamente 10,3 mil $\mathrm{km}^{2}$, é composta por 34 municípios (Instituto Brasileiro de Geografia e Estatística-Ibge, 2016a) e apresentava, em 2016, uma estimativa de 4.3 milhões de habitantes (Instituto Brasileiro de Geografia e Estatística-Ibge, 2016b). 
As regiões metropolitanas diferenciam-se também no que diz respeito aos indicadores de violência. Vitória/ES, em 2013, era a quarta capital brasileira com maiores taxas de homicídio de crianças e adolescentes por habitantes, enquanto que Porto Alegre/RS ocupava a 11 $1^{\underline{a}}$ posição no mesmo ranking. Além de Vitória, outros três municípios da região metropolitana do ES encontravam-se entre os 20 com as maiores taxas nesse indicador: Serra, na $4^{\underline{\underline{a}}}$ posição; Cariacica, na $14^{\underline{a}}$ posição; e Vila Velha, na $19^{\underline{\underline{a}}}$ posição (Waiselfisz, 2015). Uma pesquisa realizada com dados referentes ao ano de 2015 (Fórum Brasileiro de Segurança Pública, 2016) encontrou resultados distintos: Porto Alegre apresentava maior taxa de homicídio doloso na população geral que Vitória. Vitória foi considerada pela pesquisa a capital brasileira com maior diminuição da taxa de crimes violentos letais intencionais entre os anos de 2014 e 2015, enquanto que Porto Alegre apresentava um aumento de tal indicador.

\section{Participantes}

Participaram do estudo 25 adolescentes em MSE de internação, sendo 12 no ES e 13 no RS. O processo de recrutamento ocorreu por conveniência, a partir de indicação de funcionários das unidades socioeducativas. Os funcionários foram orientados a indicar adolescentes que tinham histórico de participação em atividades coletivas. Foram considerados, ademais, os seguintes critérios de inclusão: 1) idade entre 15 e 20 anos, de modo a evitar discrepâncias etárias; 2) tempo de internação superior a seis meses, tendo em vista que a pesquisa originalmente investigava as relações interpessoais estabelecidas durante a privação de liberdade; e 3) recebimento de visitas familiares, tendo em vista que a pesquisa investigava também as relações com a família. Como critério de exclusão, levou-se em consideração aspectos interpessoais relacionados às unidades socioeducativas, de modo que adolescentes com histórico frequente de conflitos com os demais não foram recrutados. Tomou-se o devido cuidado também para que adolescentes que apresentavam problemas interpessoais entre si não fossem alocados em um mesmo grupo.

Os participantes recrutados tinham entre 15 e 19 anos de idade, autodeclararam-se majoritariamente de cor parda ( $48 \% ; 36 \%$ brancos e $16 \%$ pretos) e a maioria cursava o ensino fundamental (68\%). Os nomes fictícios (apelidos) foram formulados pelos próprios participantes em uma dinâmica de produção de crachás no início das atividades. No caso de apelidos que pudessem identificá-los posteriormente, a equipe de pesquisa propôs os nomes levando em consideração características observadas. 


\section{Instrumentos}

Foi utilizado um roteiro de atividades semiestruturado que guiou a execução de grupos focais, conduzidos em duas sessões. O propósito das atividades foi investigar os projetos de vida e as relações interpessoais dos participantes. No decorrer das atividades, contudo, os adolescentes expressaram conteúdos relacionados ao mundo do crime de forma frequente e consistente. $\mathrm{O}$ trabalho traz um recorte, de modo a apresentar os significados atribuídos pelos participantes ao mundo do crime.

\section{Procedimentos}

A pesquisa foi aprovada em comitê de ética em pesquisa e encontra-se em consonância com a Resolução n⿳ํㅜ 466/2012, do Conselho Nacional de Saúde (Brasil, 2012), vigente na época. Foi também autorizada pelas presidências dos serviços socioeducativos participantes, que assinaram termos de anuência. O projeto de pesquisa foi inicialmente apresentado às equipes gerenciais e técnicas dos locais. Os adolescentes recrutados foram informados individualmente sobre os objetivos, justificativa, procedimentos e critérios éticos envolvidos com a pesquisa. Aqueles que concordaram em participar assinaram um termo de assentimento (ou consentimento, a depender da idade). No caso dos adolescentes com menos de 18 anos, os gerentes dos locais assinaram o termo de consentimento.

Foram realizados quatro grupos focais, entre março e abril de 2016. Os grupos foram compostos por seis ou sete adolescentes e a equipe de pesquisa possuía um mediador, um co-mediador e dois observadores. O mediador era do gênero masculino e tinha 26 anos. Os co-mediadores variaram conforme o Estado, possuíam entre 30 e 35 anos e eram do gênero masculino no RS e feminino no ES. Somente um grupo, no RS, foi conduzido apenas com pessoas do gênero masculino, tendo em vista que em um dos grupos no RS havia uma observadora de gênero feminino e que no ES o co-mediador era do gênero feminino. Havia membros que se autodeclararam de cor branca e parda na equipe do ES enquanto que todos os membros da equipe no RS se autodeclararam de cor branca.

O conteúdo gerado nos grupos focais foi registrado em áudio, transcrito e tratado. A organização e análise dos dados foi realizada de acordo com os passos da Análise Temática (Braun \& Clarke, 2006) e com o auxílio do software NVivo 11. Inicialmente, os trechos que se relacionavam ao objetivo foram codificados e depois agrupados por similaridade semântica. Com base nesses agrupamentos, foram formulados temas relacionados aos significados atribuídos pelos participantes ao mundo do crime. As 
unidades temáticas foram então nomeadas e descritas, sendo somente posteriormente discutidas com base na literatura científica. Os temas identificados foram verificados por dois juízes e validados por consenso.

\section{Resultados}

A análise gerou cinco temas: 1) A «boca» é como uma família; 2) A «boca» é como uma empresa; 3) $\mathrm{O}$ vínculo com a «boca» gera um contexto de perigo iminente; 4) A «boca» busca manter bons vínculos com a comunidade; e 5) A «boca» está sempre de portas abertas. «Boca» é um termo êmico identificado nesta pesquisa e recorrentemente utilizado nos territórios dominados por facções. Refere-se ao estabelecimento onde se vende drogas, mas também às pessoas vinculadas ao estabelecimento, formando uma unidade contextual associada a um ambiente físico e interpessoal. Cada tema será discutido a seguir em subseção individual:

\section{1) A boca é como uma família}

Os participantes relataram que o mundo do crime se organiza em grupos. Essas unidades organizacionais foram descritas de maneira diferente conforme a região de coleta de dados. No ES, relataram que o mundo do crime se organizava conforme o bairro de residência de seus membros. Esses grupos entravam em confronto entre si devido à disputa por territórios de venda de drogas. No RS, relataram a existência de facções que dominam diferentes regiões da cidade de Porto Alegre e, até mesmo, de municípios no interior do Estado. Esses grupos criminosos tinham nomes específicos («Manos», «Bala na Cara» etc.) e até mesmo identidade visual. A vinculação a esses grupos estava fortemente mais atrelada a aspectos identitários que no ES, havendo até mesmo adolescentes que se tatuavam com símbolos de suas facções.

Esses grupos criminosos representavam para os participantes (especialmente do RS) mais que uma organização com fins econômicos, mas também afetivos. As relações estabelecidas com os membros da mesma facção chegaram a ser até mesmo comparadas com relações estabelecidas com membros familiares: «Na real, pra nós, assim, o nosso embolamento [facção], nossa boca [estabelecimento onde se vende droga], nós somos uma família, né, seu?» (Honesto, 18 anos, RS). 


\section{2) A boca é como uma empresa}

Os adolescentes compararam o funcionamento da boca ao funcionamento de uma empresa, a qual possui funcionários com cargos administrativos e operacionais. Os participantes do ES nomearam cargos que compõem uma boca, admitindo que esses variam conforme a região e o funcionamento de cada estabelecimento: «No crime tem uma certa hierarquia. Começa no vapor, vai pro gerente, vai pro frente e o dono da boca. Aí cada qual se encaixa numa dessas funções» (Questionador, 18 anos, ES). O «vapor»é responsável pela venda da droga e o «gerente» por organizar a entrada e saída de drogas no local. $\mathrm{O}$ «frente» administra a boca e presta contas ao «dono», que em geral não trabalha diretamente no local e enriquece com o trabalho dos demais. Os participantes do RS falaram que alguns membros da boca matam, outros roubam, outros vendem a droga e outros fazem a segurança do local. Fizeram menção a um «patrão», que administra o estabelecimento e dirige funções.

Os participantes revelaram que a carreira na boca em geral se inicia com cargos operacionais, gradativamente evoluindo para cargos administrativos: «Que nem um trabalhador. Ele começa ele lidando com as máquinas, daqui a pouco ele já tá na gerência da empresa. O que ele tava fazendo, ele já não faz mais. Ele tá comandando as pessoas que 'tão fazendo» (Baderneiro, 18 anos, RS). O crescimento no mundo do crime foi associado a diversos fatores, dentre eles a necessidade de um investimento monetário inicial para comprar drogas e abrir seu estabelecimento próprio. Mencionaram a possibilidade de crescimento em uma boca já existente a partir do relacionamento positivo com o dono/patrão. Ao cumprir «missões» [tarefas] com sucesso e matar «inimigos»/«contras», chamam a atenção do dono/patrão, que pode oferecer cargos administrativos com melhor remuneração. Da mesma forma, o desempenho de funções sem sucesso está vinculado a «demissões». Outra possibilidade de crescimento é a partir da herança de um cargo ocupado por alguém que morreu.

O crescimento no mundo do crime, segundo os adolescentes, estava relacionado a um conjunto de características pessoais que qualificavam um «bom traficante»: «Minha característica boa que eu sei fazer bem o que eu faço. Sei viver bem no crime, não tremo, sei lidar com as drogas e o dinheiro» (Baderneiro, 18 anos, RS). Para os interlocutores da pesquisa, um bom traficante deve ser inteligente, humilde, pensar com clareza, ter habilidades de gestão, conhecer e tratar bem os funcionários da boca, saber em quem pode confiar e ter responsabilidade na gestão do estabelecimento, assim como um empresário gere uma empresa. Ademais, ele deve evitar o recrutamento de pessoas 
usuárias de drogas (especialmente o crack), percebidas como inclinadas a não cumprir obrigações e se endividar.

\section{3) O vínculo com a boca gera um contexto de perigo iminente}

Os participantes revelaram que o pertencimento a uma facção está associado ao estabelecimento de inimizades com integrantes de facções rivais. Isto porque, no exercício das funções na boca, é comum o cometimento de homicídios, de modo que pessoas próximas à vítima tendem a buscar o autor da agressão para se vingar. A entrada no mundo do crime é vista, assim, como um «caminho sem volta»: «Eu não quero largar o crime, porque cobrança [vingança] gera cobrança. Eu tenho guerra, daí eu vou cobrar um. Vai ter outro parente dele que vai tá no crime, vai querer me cobrar também» (Baderneiro, 18 anos, RS).

Os adolescentes relataram que, ainda que decidam se desligar da boca e trabalhar licitamente, os antigos inimigos podem aparecer a fim de retaliar agressões anteriores. Tal contexto de ameaça motiva os adolescentes a permanecerem vinculados a seus pares também em conflito com a lei: «Então prefiro tá no crime, tá com os caras que eu sei que vão me proteger se der uma ladaia. Eu vou ter meu porte, vou ficar sereno. Dentro da minha boca, eu sei que ali tou protegido» (Honesto, 18 anos, RS). Os adolescentes acrescentaram que, ante a este dilema, é preferível morrer em «combate» que como um «trabalhador». O contexto permanente de perigo iminente motiva os adolescentes a viverem em estado de alerta e andarem armados. Com isto, correm o risco de serem «pegos pela polícia» por porte ilegal de armas. Tal situação de perigo constante leva a um cotidiano de restrição de liberdade, uma vez que locais devem ser evitados, por serem frequentados por pessoas de grupos rivais.

Os adolescentes assinalaram que o perigo iminente também é gerado em função do risco de violência perpetrada por membros da própria boca. Indicaram como razão para a perpetração da violência o desrespeito, transgressões a normas, descumprimento de obrigações e dívidas não pagas. Mencionaram o risco de traição, em especial por pessoas em cargos de maior poder na hierarquia da boca: «Aí tu vai estar de bobão no bagulho, os caras vão vim e vão te matar, teu próprio amigo vai lá e te mata» (Zeus, 17 anos, RS). Esta é uma forma de ocupar cargos com maior hierarquia entre seus pares. 


\section{4) A boca busca manter boas relações com a comunidade}

Os participantes do RS revelaram que as facções buscam manter boas relações com as comunidades em territórios dominados, manifestadas por meio do fornecimento de bens materiais e de proteção física, como em situações de violência doméstica e roubos na comunidade: «Na boca, os cara têm um mercado que é da boca. Daí os morador vêm, tá precisando de um bagulho. 'Viu, vai lá e pega na conta da boca', os caras botam» (Honesto, 19 anos, RS). Tais situações foram descritas como benéficas aos moradores, além de evitar a entrada de polícia no território. Foram descritas regras para assegurar a segurança de crianças, evitando, por exemplo, trocas de tiro próximas a escolas, bem como a venda de drogas para mulheres que recentemente tiveram filhos. Essas situações colocam o dono/patrão como uma forma de «juiz», delegando sentenças a pessoas que violam os acordos. As sentenças podem variar desde espancamentos, a mutilações e assassinatos.

Os adolescentes relataram que os moradores de comunidades em territórios dominados devem retribuir às facções com expressões de lealdade e cumplicidade. Portanto, fornecem refúgio quando da fuga de polícia, testemunham a favor em juízo, armazenam artefatos para a facção em suas casas, ou dificultam a entrada de polícia no território: «O cara tá sempre com o morador do lado. Se vem os home [polícia] pra se espichar ou um bagulho assim, os morador salta pra rua, faz mó ladaia [bagunça]» (Honesto, 19 anos, RS).

Os adolescentes alegaram ainda que a mídia transmite informações equivocadas sobre o mundo do crime. Segundo os participantes, moradores e traficantes são como uma grande família, apoiando-se mutuamente: «O embolamento e a comunidade é uma família. Todo mundo junto. Um apoia o outro» (Mata Rindo, 19 anos, RS). Os adolescentes retrataram como falsa e tendenciosa a ideia de integrantes de facções violando direitos de moradores, retratando apenas casos pontuais e pouco representativos da realidade de suas comunidades.

\section{5) A boca está sempre de portas abertas}

Os participantes afirmaram que o vínculo com o mundo do crime permite o acesso a produtos de sobrevivência básica e a bens de consumo. Relacionaram o envolvimento com atividades ilícitas a um contexto prévio de privação de recursos, de modo que o retorno financeiro rápido muda as condições econômicas precárias usualmente enfrentadas por famílias em situação de vulnerabilidade social e econômica. As 
possibilidades no mercado de trabalho fora do tráfico foram retratadas como escassas, mal remuneradas e marcadas por experiências de desvalorização, humilhação, exploração e sofrimento. O mercado de trabalho foi descrito como excludente, com melhores empregos comumente associados às exigências de escolaridade e profissionalização critérios esses não preenchidos por muitos dos adolescentes. $\mathrm{O}$ mundo do crime, por sua vez, não exige tais critérios, de modo que suas «portas estão sempre abertas». Esse contexto de «ausência de oportunidades» favorece a vinculação com o mundo do crime como estratégia de sobrevivência econômica: «É o sustento de muita gente. Tem gente que não gosta, não sabe fazer nada a não ser fazer o crime. O bagulho é o crime» (Trem Bala, 18 anos, RS).

Para além do acesso a bens de consumo, os adolescentes acrescentaram que a vinculação com o mundo do crime favorece também um local de prestígio na comunidade a partir de práticas de ostentação. Nesse sentido, fazer parte de uma boca é associado a poder, acesso a bens de consumo e status: «Você não liga para o que você gasta. Aquilo que você gasta hoje, amanhã ganha de novo» (Usuário, 17 anos, ES). Os participantes revelaram ainda que a vinculação com o mundo do crime também envolve uma forma de prazer ao andar armado e cometer atos infracionais, o que gera uma sensação descrita como «adrenalina».

\section{Discussão}

O presente trabalho partiu da seguinte questão de pesquisa: Quais os significados atribuídos ao mundo do crime por adolescentes em MSE de internação? A partir do relato dos participantes, foram identificados cinco núcleos semânticos que elucidam a questão: 1) As relações estabelecidas na boca envolvem trocas afetivas, como em uma família; 2) A organização da boca é semelhante à organização de uma empresa, com distribuição de cargos e possibilidade de crescimento profissional; 3) A vinculação com a boca gera um contexto de perigo iminente que pode conduzir ao combate armado e, por vezes, a morte; 4) A boca possui boas relações com os territórios sob os quais possuem domínio; e 5) O envolvimento com a boca é uma possibilidade alternativa ao mercado de trabalho, que possui critérios de inclusão mais restritos. Esses núcleos semânticos se articulam entre si, de modo a compreender a imersão no mundo do crime como um fenômeno complexo e permeado por fatores sociais, econômicos e subjetivos. 
Ao significarem o mundo do crime, os adolescentes descreveram um contexto de privação de recursos que antecede a prática do ato infracional. Isto fica evidente sobretudo no entendimento da boca como sempre de «portas abertas», isto é, como possibilidade alternativa ao mercado de trabalho frequentemente excludente para esses adolescentes. Nesse sentido, a vinculação ao tráfico de drogas favorece o acesso a produtos de sobrevivência básica e bens de consumo. Os achados corroboram a compreensão de outros autores sobre o tema, tais como Zaluar (2012), que interpreta a sociabilidade violenta de adolescentes no mundo do crime como possível resultado de um contexto de desigualdade social e permeado pela cultura do consumo.

Os adolescentes descreveram o acesso a recursos a partir do desenvolvimento de carreiras associadas às facções, tendo em vista que a boca foi compreendida «como uma empresa». Nesse sentido, além de alternativa ao mercado de trabalho lícito, a boca oferecia aos adolescentes uma espécie de «identidade de carreira» associada ao mundo do crime. Isto significa dizer que a vinculação com a boca ofereceria não somente retornos materiais, mas também simbólicos, a partir do fortalecimento da identidade pessoal. Esta perspectiva corrobora o processo de «sujeição criminal» descrito por Misse (2010), no sentido de atribuir um sentido de agência a esses adolescentes. A imersão no mundo do crime torna-se, pois, não somente uma reação diante de um contexto adverso, mas uma ação diante da experiência de exclusão.

Os participantes atribuíram ao mundo do crime uma espécie de posição de privilégio na comunidade, o que denota também a importância da boca nos territórios dominados. Isto fica evidente no entendimento de que a boca mantinha «boas relações com a comunidade», de modo a compreender o patrão do estabelecimento como um líder na comunidade. Essas relações foram compreendidas sobretudo como uma espécie de «troca de favores» nos quais a boca oferece recursos em troca do apoio da comunidade. De modo semelhante, Lessing (2008) observou a perpetuação de ações assistenciais por facções no RJ como meio de garantir a cumplicidade dos moradores com a criminalidade.

As ações da boca chegavam ao ponto de estabelecer uma espécie de júri local como substituto ao Poder Judiciário, motivadas principalmente pela tentativa de evitar a entrada da polícia nos territórios dominados. Do ponto de vista dos participantes, este era um meio de garantir a segurança local, o que reforçava a visão positiva acerca da boca e suas ações na comunidade. Todavia, Mattos (2016), partindo da perspectiva de moradores de periferia no RJ, descreveu o exercício das funções jurisdicionais por 
membros de facções como frequentemente perpetradoras da injustiça e efetuadas a partir do uso da violência. As diferenças de perspectivas entre moradores e membros de facções podem revelar uma espécie de idealização do mundo do crime pelos participantes, para quem as facções representam mais que uma organização criminosa.

A boca oferecia aos participantes uma espécie de pertencimento e reconhecimento social, seja por meio do reconhecimento externo por moradores da comunidade, seja devido à vinculação com pares com quem dividiam valores. A descrição da boca «como uma família» deixa claro o efeito afetivo que as pertenças relacionadas ao mundo do crime exercia sobre os participantes. Este aspecto é de particular importância ao se considerar que a adolescência é o período da vida em que o indivíduo busca outros referenciais que não somente os oriundos no núcleo familiar. A vinculação com os pares torna-se, assim, fundamental no desenvolvimento de valores e na constituição de sua identidade (Erikson, 1976).

Os efeitos identitários da pertença ao mundo do crime foram observados com maior intensidade entre os participantes em Porto Alegre/RS, o que pode se relacionar a diferenças no modo de organização das facções nos Estados. No RS, as facções tomavam grandes proporções, dominando territórios em bairros de diferentes regiões de Porto Alegre, chegando mesmo a municípios do interior. No ES, o mundo do crime era organizado em nível geográfico e sem uma «guerra aberta» declarada, como era há alguns anos no RS (Cipriani, 2016) e na década de 1990 no RJ (Mattos, 2016). No RJ, esses pequenos mercados ilícitos gradativamente formaram alianças, que se tornaram as facções conhecidas hoje como «Comando Vermelho», «Amigos dos Amigos», entre outras (Mattos, 2016). De modo semelhante, o RS observou nos últimos anos o crescimento de suas facções (Cipriani, 2016), o que possivelmente possui relação com o aumento das taxas locais de homicídio (Fórum Brasileiro de Segurança Pública, 2016), seja pelas práticas de latrocínio, seja pelas chamadas «guerras do tráfico».

As guerras do tráfico relacionam-se ao contexto de «perigo iminente» descrito pelos participantes. Todavia, a situação de risco parece exercer um efeito de fortalecimento dos vínculos com o mundo do crime, como forma de obter a proteção de seus pares. Simultaneamente, a morte em combate é entendida como um sinal de honra. Ao descrever as etapas de imersão de adolescentes no mundo do crime, Feltran (2008) situa a aceitação radical da própria morte como efeito do envolvimento cotidiano em situações de combate com a polícia e com facções rivais. Retomando a ideia de «sujeição criminal» proposta por Misse (2010), a aceitação da morte precoce é encarada como mais 
uns etapa da vida no crime, como uma escolha em viver de modo intenso e rápido. A imersão no mundo do crime promove, pois, o encurtamento do tempo de vida, mas oferece uma vida mais vantajosa que a do «trabalhador» - que viveria muito, mas sem recursos, sem status e sem poder.

Os resultados indicam que o envolvimento com o mundo do crime atende a necessidades de segurança econômica, fortalecimento da identidade pessoal, reconhecimento social, senso de pertencimento e proteção física. Nesse sentido, o envolvimento de adolescentes com o mundo do crime pode ser compreendido como um processo de resiliência oculta (Pessoa et al., 2017). Isto é, o envolvimento com o narcotráfico é inicialmente pensado, a partir de critérios normativos, como uma espécie de comportamento de risco - tendo em vista que se associa a desfechos negativos. Todavia, a pertença ao mundo do crime possibilita também o acesso a recursos materiais e simbólicos ausentes em um contexto pregresso de exclusão, configurando-se, pois, como um modo de enfrentamento e superação da adversidade.

O potencial de generalização (ou transferibilidade) de achados resultantes de pesquisas qualitativas é diretamente dependente da descrição detalhada das características e contexto da realização da pesquisa, bem como da similaridade de tais características com outros possíveis contextos de aplicação. Neste sentido, é necessário destacar que os grupos focais foram realizados em unidades socioeducativas em duas regiões metropolitanas brasileiras escolhidas por conveniência e que não representam a realidade nacional ou das unidades socioeducativas fora das regiões metropolitanas de seus respectivos Estados. Ainda assim, foi possivel destacar achados comuns a ambos os contextos de pesquisas e que também são comuns aos achados de pesquisas conduzidas nos mesmos Estados e em outras localidades. Essa similaridade pode, portanto, indicar um potencial de generalização da realidade descrita a outros grandes centros urbanos.

Os resultados podem contribuir para o planejamento de intervenções com adolescentes em MSE, de modo a enfocar, sobretudo, no atendimento das necessidades materiais e simbólicas dos adolescentes a partir de meios lícitos. Ações profissionalizantes com retorno financeiro em curto prazo podem contribuir para a segurança econômica. Programas de caráter comunitário devem oferecer aos adolescentes novas possibilidades de inserção social, de modo a possibilitar o desenvolvimento de identidades das quais os adolescentes se orgulhem. Para garantir a proteção física seria necessário promover tanto ações de segurança comunitária em seus próprios territórios de residência e convívio como centros de convivência e programas de mediação de conflitos - como programas 
que auxiliem os adolescentes que optem por mudar para outras regiões como forma de escapar da violência associada ao mundo do crime em seus bairros. $O$ auxílio desses programas deve ocorrer não somente em nível material, mas também simbólico - tendo em vista que a mudança para novos territórios pode gerar nos adolescentes dificuldades de adaptação.

Para conduzir investigações de perspectivas êmicas é necessário ter cuidados éticos e metodológicos para estabelecer uma relação de transparência, confiança e confidencialidade, com uma postura de interesse e não judicativa, sem culpabilizar os adolescentes ou repreender suas falas, garantindo a livre expressão dos interlocutores da pesquisa. A utilização de grupos focais demonstrou atender a tais necessidades. Estudos futuros podem testar diferentes estratégias metodológicas capazes de informar conteúdos êmicos e verificar a qualidade das informações produzidas por cada método de pesquisa. Outros estudos podem testar a aplicação de conhecimentos de origem êmica nas práticas de atendimento a adolescentes no sistema socioeducativo, com vistas a possibilitar o atendimento de necessidades materiais e simbólicas dos adolescentes por meios lícitos e com menor exposição a riscos.

\section{Agradecimentos}

Agradecemos à Capes pela bolsa ofertada aos dois primeiros autores. Agradecemos ao CNPq, pela bolsa ofertada à terceira e à quarta autora. Agradecemos à Fapes, pela taxa de pesquisa oferecida à terceira autora. Agradecemos à Fase-RS e ao Iases (órgãos responsáveis pelo atendimento socioeducativo no RS e ES, respectivamente), que gentilmente possibilitaram a coleta de dados da pesquisas. Agradecemos a Carolina Milanezi Manzini de Souza, Danielly Bart do Nascimento, Júlio Storch, Matheus Castro, Maurício Pinto Marques, Odacyr Roberth Moura da Silva e Roberta Francieli da Silva ,membros da equipe de pesquisa que fizeram parte da coleta de dados.

\section{Referências}

Azevedo, R. R., \& Cipriani, M. (2015). Um estudo comparativo entre facções: o cenário de Porto Alegre e o de São Paulo. Sistema Penal \& Violência, 7(2), 16o-174. https:// doi.org/10.15448/2177-6784.2015.2.22162 
Brasil. (1990). Lei federal no 8.069, de 13 de Julho de 1990. Dispõe sobre o Estatuto da Criança e do Adolescente e dá outras providências. Brasília, D. F.: Diário Oficinal da União.

Brasil. (2012). Resolução nº 466, de 12 de Dezembro de 2012. Brasília, D. F.: Diário Oficinal da União.

Braun, V., \& Clarke, V. (2006). Using thematic analysis in psychology. Qualitative Research in Psychology, 3, 77-101. https://doi.org/10.1191/1478088706qpo63oa

Candelas, M. A. (2016). La construcción socio-histórica de la "infancia peligrosa" en España. Revista Latinoamericana de Ciencias Sociales, Niñez y Juventud, 14(1), 95-106. https://doi.org/10.1160o/1692715x.1417090915

Cipriani, M. (2016). Da «Falange Gaúcha» aos «Bala nos Bala»: a emergência das «facções criminais» em Porto Alegre/RS e sua manifestação atual. Direito e Democracia, 7(1), 105-130.

Erikson, E. H. (1968/1976). Identidade, juventude e crise. (A. Cabral, Trans.) Rio de Janeiro: Zahar.

Feltran, G. S. (2008). O legítimo em disputa: as fronteiras do mundo do crime nas periferias de São Paulo. Dilemas: Revista de Estudos de Conflito e Controle Social, 1(1), 93-148.

Feltran, G. S. (2011). Jovens em conflito com a lei. Revista de Antropologia Social dos Alunos do Ppgas-UFSCar, 3(1), 259-267.

Fórum Brasileiro de Segurança Pública. (2016). Anuário de segurança pública 2016. São Paulo: Autor.

Instituto Brasileiro de Geografia e Estatística. (2016a). Área territorial oficial. Rio de Janeiro: Autor.

Instituto Brasileiro de Geografia e Estatística. (2016b). Estimativas da população residente nos municípios e para as unidades da federação brasileiros com data de referência em $1^{\circ}$ de julho de 2016. Rio de Janeiro: Autor.

Jimenez, L., Andrade, E. M., \& Bianchini, L. G. B. (2016). Uso de drogas e ato infracional: Revisão integrativa de artigos brasileiros. Revista Latinoamericana de Ciencias Sociales, Niñez y Juventud, 14(2), 939-955. https://doi.org/10.11600/1692715x.1417090915

Jimenez, L., \& Frasseto, F. A. (2015). Face da morte: a lei em conflito com o adolescente. Psicologia \& Sociedade, $27(2), 404-414$. https://doi.org/10.1590/1807-03102015v27n2p404

Lessing, B. (2008). As facções cariocas em perspectiva comparativa. Novos Estudos Cebrap, (80), 43-62. https://doi.org/10.159o/s0101-33002008000100004

Mattos, C. S. (2016). Uma etnografia da expansão do mundo do crime no Rio de Janeiro. Revista Brasileira de Ciências Sociais, 31(91), 1-15. https://doi.org/ $10.17666 / 319110 / 2016$ 
Misse, M. (2010). Crime, sujeito e sujeição criminal: aspectos de uma contribuição analítica sobre a categoria «bandido». Lua Nova: Revista de Cultura e Política, (79), 15-38. https://doi.org/10.1590/s0102-64452010000100003

Pessoa, A. S. G., Coimbra, R. M., Noltemeyer, A., \& Bottrell, D. (2017). The applicability of hidden resilience in the lives of adolescents involved in drug trafficking. En D. D. Dell'Aglio, \& S. H. Koller (Eds.), Vulnerable children and youth in Brazil (pp. 247-26o).

New York: Springer. https://doi.org/10.1007/978-3-319-65033-3_16

Poletto, M., \& Koller, S. H. (2008). Contextos ecológicos: promotores de resiliência, fatores de risco e de proteção. Estudos de Psicologia, 25(3), 405-416. https://doi.org/ $10.1590 / \mathrm{s0103}-166 \times 2008000300009$

Rolim, M. (2014). A formação de jovens violentos: para uma etiologia da disponibilidade violenta. (Tese de Doutorado). Programa de Pós-Graduação em Sociologia da Universidade Federal do Rio Grande do Sul, Porto Alegre, RS., Brasil.

Stake, R. E. (2006). Multiple case study analysis. Nueva York: Guilford Press.

Ungar, M. (2004). Nurturing hidden resilience in troubled youth. Toronto: University of Toronto Press. https://doi.org/10.3138/9781442677975

Valdenegro, B., \& Calderón-Flández, C. (2016). Alteridad, Infancia y delincuencia: análisis discursivo desde programas sociales hacia infancias en Chile. Revista Latinoamericana de Ciencias Sociales, Niñez y Juventud, 14(2), 1191-1204. https://doi.org/ 10.11600/1692715x.14221070714

Waiselfisz, J. J. (2015). Mapa da violência 2015: mortes matadas por armas de fogo. Rio de Janeiro: Flacso.

Zaluar, A. (2012). Juventude violenta: processos, retrocessos e novos percursos. Dados, 55(2), 327-365. https://doi.org/10.1590/s0011-52582012000200003 